\title{
A National Point-of-Care Ultrasound Competition for Medical Students
}

\author{
Creagh Boulger, MD \\ Department of Emergency Medicine, The Ohio State \\ University Wexner Medical Center, Columbus, \\ Ohio USA \\ Rachel B. Liu, MD \\ Department of Emergency Medicine, Yale University \\ School of Medicine, New Haven, Connecticut USA
}

\section{Giuliano De Portu, MD}

Department of Emergency Medicine, University of

Florida College of Medicine, Gainesville, Florida USA

Nik Theyyunni, MD

Department of Emergency Medicine, University of

Michigan Medical School, Ann Arbor, Michigan USA

\section{Margaret Lewis, MD}

Department of Emergency Medicine, Carolinas Medical Center, Charlotte, North Carolina USA

Resa E. Lewiss, MD

Department of Emergency Medicine, Thomas Jefferson University, Philadelphia, Pennsylvania USA

\section{Zachary P. Soucy, DO}

Department of Emergency, Dartmouth-Hitchcock Medical Center-Geisel School of Medicine, Hanover, New Hampshire USA

\begin{abstract}
Vi Am Dinh, MD
Departments of Emergency Medicine and Internal Medicine, Division of Pulmonary and Critical Care, Loma Linda University Medical Center, Loma Linda, California USA
\end{abstract}

\begin{abstract}
Alan Chiem, MD, MPH
Department of Emergency Medicine, Olive View-UCLA Medical Center and David Geffen School of Medicine at UCLA, Los Angeles, California USA
\end{abstract}

\section{Sara Singhal, MD}

US Acute Care Solutions, Springfield, Ohio USA

\author{
Donald Di Salvo, MD \\ Department of Radiology, Harvard Medical School, \\ Boston, Massachusetts USA
}

John S. Pellerito, MD

Department of Radiology, Hofstra Northwell School of Medicine, Northwell Health System, Hempstead, New York USA

\section{David Bahner, MD \\ Department of Emergency Medicine, The Ohio State University Wexner Medical Center, Columbus, Ohio USA}

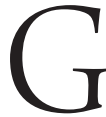
aming is a teaching concept that is gaining momentum in the medical education community. Gamification events motivate asynchronous self-study of ultrasound (US), evidenced by the narrative comments received from surveys. Students and faculty from different specialties and multiple varied institutions have found value from this platform to exchange content, discuss curricula, highlight obstacles to implementation, and
} 
share success stories. These fun educational gaming events remove barriers that may exist in the traditional curricular setup. Medical educators traditionally use passive methods for content dissemination via textbooks, teacher-driven lectures, viewing of online screencasts, and testing of knowledge retention. Recent studies of adult learners suggest that these methods may not be the optimal means for educating this population. ${ }^{1-4}$ As technology increases access to information, so too does the volume of content a medical student receives. How does an educator combat the challenge of delivering more content within an increasingly burdened curriculum? Recent approaches have relied on students' independent and blended learning through asynchronous learning tools and a "flipped classroom" structure to cover advanced exploration or skill practice during actual class time. These methods still incorporate a degree of passive learning, whereas adult learners benefit more from active engagement. ${ }^{5-7}$ The incorporation of game playing to introduce and solidify new medical skills can address these challenges.

The movement to implement point-of-care US as a core skill for medical students began in 2006. Point-of-care US use has been shown to be a feasible method of integrating basic science teaching, while simultaneously augmenting physical examination performance and clinical reasoning through active handson US scanning. ${ }^{8-13}$ Although relatively simple to understand, US imaging requires a new set of spatial orientation and proprioceptive skills. It also requires deliberate practice. The integration of point-of-care US into longitudinal medical curricula is still young. ${ }^{14-17}$ No standardized method for point-of-care US training currently exists. Each medical school takes a different approach, using faculty from varied specialties. The concept of developing a contest with students from across the country highlights the enthusiasm for learning point-of-care US, the strength of faculty collaboration, and the increasing extent of gamification in medical education.

The Ultrasound Challenge was the first documented US competition among medical students at a single institution. The Ultrasound Challenge 2.0 described a US competition from multiple medical schools. ${ }^{22,23}$ Emergency medicine developed a specialty-specific US competition in 2011 called SonoGames, which targeted the graduate medical education level. Since then, this annual event has attracted participants from more than 50\% of emergency medicine residency programs. Subsequently, residencies started incorporating similar competitions into their weekly didactics, and then local medical student competitions called "Ultrafests," "SonoCups," and "Sono-Olympics" began appearing across the nation. ${ }^{22-25}$ SonoSlam was developed as an annual national medical student competition to promote point-ofcare US to the undergraduate medical community in a friendly aca-

doi:10.1002/jum.14670

Abbreviations

AIUM, American Institute of Ultrasound in Medicine; US, ultrasound demic environment. 


\section{Planning}

The SonoSlam Executive Committee is a multispecialty committee composed of experienced US faculty from across the country. Many have developed their own regional US events or helped design national events. Seven vendors provided US equipment. Online supplemental Appendix A provides a list of SonoSlam's sponsors. The Executive Committee received Institutional Review Board-exempt approval to evaluate this event through The Ohio State University.

\section{Recruitment}

Student participants were invited through the National Ultrasound Student Interest Group listserv and website communications, the American Institute of Ultrasound in Medicine (AIUM) member listserv, a website announcement, and letters to medical school leadership. SonoSlam was also promoted through social media and by word of mouth. Volunteer models for the stations were recruited in a similar fashion. Proctors from AIUM membership represented faculty from emergency medicine, internal medicine, radiology, pediatrics, critical care, neurology, and sonographers. Preparation materials and instructions were sent to all faculty proctors ahead of time. This process allowed standardization of teaching among the stations.

In 2016, 17 teams from 12 medical schools competed. Each team consisted of 3 students. In 2017, 23 teams representing 17 schools competed (online supplemental Appendix B). Students in both preclinical and clinical years participated and completed postevent surveys (online supplemental Appendix C) with free-text comments displayed in online supplemental Appendix $\mathrm{D}$ and specific survey results in online supplemental Appendixes E and F.

\section{Event Layout}

\section{Round 1}

The Executive Committee designed a series of stations that combined open-ended, quiz-style questions with hands-on US scanning based on anatomic regions. The stations were chosen to appeal to a student's broad range of knowledge in preclinical years, as well as multiple specialists' fields of expertise. Questions targeted basic science elements and physical examination correlations that students encounter in the preclinical component of their education. Topics included: physics and knobology, head and neck, cardiac, aortic, musculoskeletal, hepatobiliary, renal, and obstetrics and gynecology. Final questions for each station were peer reviewed and selected by using an iterative Delphi process. This first round was modified in the second year of the event on the basis of participant feedback. In a survey following the initial event, students requested to have a scored hands-on component to round 1. Content was also adjusted to reflect the appropriate level of difficulty for their level of training. In the second year, students earned points for scanning ability. Judges had a Google form with knowledge-based questions as well as scanning tasks. The scanning tasks were scored as correct or not. Judges were given guidance as to what entailed a correct scan to minimize inter-rater variability among judges. In the second year, teaching was done via scheduled station debriefs.

In the 2016 competition, teams were given a 5question knowledge assessment via Google Form on their phones. After this assessment, station faculty led them through a series of 15-minute hands-on educational scanning sessions augmented by brief PowerPoint (Microsoft Corporation, Redmond, WA) presentations. The scanning component was not graded, but proctors took note of particular students and teams who displayed image acquisition prowess or proficiency with advanced concepts. This portion was modified in 2017 so that teams rotated every 15 minutes through each station without a PowerPoint presentation. Teams were graded by a combination of correct answers provided during the quiz portion of the station (fill-in-the-blank questions) and completion of scanning tasks. Point totals were tabulated in real time by using a Google Form platform designed to calculate team scores. Once scores were submitted, expert proctors reviewed the quiz answers with the teams and offered feedback on their scanning techniques.

In the first year of this event, round 1 was used to eliminate a portion of the teams. In 2017, all teams progressed to round 2 .

\section{Round 2}

Round 2 tested hands-on skills in a head-to-head series of 5 game stations. These stations incorporated clinical scenarios that were designed to match and evaluate students' progression into medical student years 3 and 4 . 
Each station required score sheets that totaled up to 100 points, with specific instructions given to station proctors to ensure consistency in scoring. Teams received 3 minutes of station explanations and rules, 15 minutes of competition time, and 2 minutes for debriefing before rotating to the next station. In each station, the students rotated responsibilities to avoid having a single student perform all of the scans.

\section{6}

Station 1: SonoSkeleton

One team member blindly chose a ping-pong ball labeled with an anatomic structure out of a bucket that held 100 labeled balls. A second team member had to accurately scan the structure on a volunteer model. The third team member assisted in directing the scanner. Each accurately identified structure was worth 1 point.

Station 2: Help! I Need a Doctor ... or a Medical Student

This station used the LiveScan product (SonoSim, Inc, Santa Monica, CA), with 5 clinical scenarios (20 points each) representing patients in shock created by the company specifically for SonoSlam. They created a scoreboard divided into 3 columns: diagnosis, US pathology, and treatment. Students attached flash cards to the scoreboard, matching correct diagnoses with preprogrammed pathologic conditions (found by SonoSim probe detection of radiofrequency identification tags affixed to a volunteer model) and treatment plans. Points were awarded for each correct matching scoreboard placement.

Station 3: A Pain in My Belly

Team members needed to correctly identify abdominal anatomy and disorders shown on PowerPoint slides, characterize images as normal or pathologic, and finally scan the appropriate structure on a volunteer model. Ten case-based scenarios (10 points each) were created, which required structure identification, image acquisition, and image interpretation.

Station 4: The Nerve of These People!

Six clinical scenarios (15 points each) described patients with specific injuries that required nerve blocks for analgesia. Team members received points for correctly naming the nerve that needed to be blocked for each case, describing the dermatomal distribution of that nerve, and identifying the approach to performing the nerve block. An additional 10 points were awarded if each member of the team successfully simulated a nerve block using a low-fidelity model (linguine noodles placed in tofu).

\section{Station 5: The Land Down Under}

The Scantrainer (MedaPhor North America, Inc, San Diego, CA), a haptic transvaginal pelvic simulator device, tested students on 2 computerized cases. The first case detailed a pathologic obstetric case, and the second focused on nonpregnancy gynecologic disorders. Each case consisted of 10 tasks, which included proper insertion and positioning of the endocavitary probe, identification of relevant structures, and identification of pathologic conditions. Each correctly completed task was awarded 5 points, for a total of 50 points per case and 100 points per station.

\section{7}

As in 2016, there were 5 stations in round 2.

\section{Station 1: SonoMini}

This station used the SonoSim LiveScan product, with 5 clinical scenarios (20 points each) representing pediatric patients created by the company specifically for SonoSlam. They created a scoreboard divided into 2 columns: diagnosis and treatment. Students were given a stem and were tasked with scanning to identify pathologic conditions (found by SonoSim probe detection of radiofrequency identification tags affixed to a volunteer model) and then to state the indicated treatment plan. Points were awarded for each correct matching scoreboard placement.

\section{Station 2: SonoCharades}

This station divided the team into 3 individual roles. One member was given a structure or a clue about a structure. The participant would acquire the image, and other members had to guess what the target structure was based on a saved image without being able to point or give any further clues. The scanner was not able to talk or gesture but rather merely improve the image to facilitate guessing the correct answer. Points were awarded for correct answers.

Station 3: Hit or Miss

Using a simulator provided by Kyoto Kagaku America, Inc (Torrance, CA), and homemade phantoms, the students had to scan and identify foreign bodies and lesions. 
The other team members then needed to biopsy the sample in plane and out of plane. In the homemade phantom, team members had to find foreign bodies representing US artifacts of shadowing and reverberation. Teams received bonus points for correctly identifying the foreign bodies.

\section{Station 4: Put Me in Coach}

This station focused on musculoskeletal disorders. In this station, student 1 would review a US clip of a particular disorder and identify it. Student 2 was then responsible for identifying the normal version of the structure on a model. Student 3 demonstrated a physical examination maneuver to assess for the disorder. Students rotated through roles.

\section{Station 5: US Password}

This station assessed communication skills and US knowledge. Student 1 selected a slip of paper with a US structure (ie, transverse proximal aorta). Student 2 was a blindfolded sonographer. Student 1 had to give clues to student 2 and student 3 without naming the structure or saying "forbidden words" mentioned on the slip of paper. Once the structure was correctly identified, student 3 had to give instructions to student 2 to obtain the structure on a model. Student 3 had to freeze the image once he or she thought it was correct. Students rotated with each new image.

The 2 teams with the highest scores after round 2 advanced to the final round 3 .

\section{Round 3}

Round 3 began with a "peel-and-reveal" tile game, in which a short case scenario was verbally delivered to the teams while its accompanying US clip was displayed on a screen visible to both teams. Small obscuring squares covered the image and were slowly removed in random order. The first team to correctly identify the image was awarded points dependent on the number of remaining tiles. There were 10 cases for the peel-and-reveal game; additional bonus points were awarded after each case to the team that correctly answered corresponding clinical management questions.

Round 3 ended with a "scan-off," in which a member from each team entered a concealed area to demonstrate a specific structure on a live model. Models were matched by US faculty for body habitus and US windows. The audience was blinded to the teams scanning and was polled to determine which scan was most accurate. The student who performed the most-accurate scan won points for his or her team. The team accruing the most points at the end of round 3 became the overall winner of SonoSlam.

\section{Sonologist}

In addition to the team awards, individual scanning ability was recognized. Throughout the event, 4 unidentified experts circulated the room, watching teams scan. These experts noted participants who consistently demonstrated excellent scanning techniques (good hand position, grip, anchoring, draping, and probe manipulation) and repeatedly acquired high-quality images (appropriate probe, mode, depth, gain, and centering of key structures). These 4 expert judges compared their results to establish which student would win the SonoSlam Sonologist Award.

\section{Summary}

SonoSlam is a multispecialty US competition for medical students. It has proven to be a feasible and successful method of stimulating interest in medical school US education and encouraging lifelong learning habits through active participation. During this 1-day event, students reported improved confidence in general knowledge, image acquisition, and overall performance, including clinical management decisions. These techniques allowed students to delve into subject material that was completely novel to them. As technological advancements increase accessibility to point-of-care US education at student and faculty levels, events such as SonoSlam bridge knowledge and skill gaps in enjoyable ways.

The third SonoSlam event was held March 24, 2018, at the AIUM Annual Convention in New York City. Future efforts will focus on sustainability of this event and streamlining of logistic processes involving vendor support, funding, faculty support, space, and the financial burden on students for travel and participation. The committee also plans to host a networking event for students and faculty in addition to a 1-day US "boot camp" the day after the event. This event will allow students to review content from the competition and attend lectures on implementation of US into curricula and hands-on sessions on clinical applications. In addition, the committee hopes to measure the objective impact of 
events such as these have on knowledge acquisition, technical skill improvement, and information retention, although the means for this process have yet to be established. Finally, the national scalability of the SonoSlam event and its effect on expansion of US teaching and standards of teaching will be surveyed.

\section{References}

1. Mehta NB, Hull AL, Young JB, Stoller JK. Just imagine: new paradigms for medical education. Acad Med 2013; 88:14181423.

2. Kahn MJ, Maurer R, Wartman SA, Sachs BP. A case for change: disruption in academic medicine. Acad Med 2014; 89:1-4.

3. Ruiz JG, Mintzer MJ, Leipzig RM. The impact of E-learning in medical education. Acad Med 2006; 81:207-212.

4. Cooke M, Irby DM, Sullivan W, Ludmerer KM. Medical education: American medical education 100 years after the Flexner report. $N$ Engl J Med 2006; 355:1339-1344.

5. Benshoff JM, Lewis HA. Nontraditional college students. In: ERIC Digests. Ann Arbor, MI: University of Michigan; 1992.

6. Tinto V, Vincent E. Classrooms as communities: exploring the educational character of student persistence. J Higher Educ 1997; 68:599623.

7. Ramar K, De Moraes AG, Selim B, Holets S, Oeckler R. Effectiveness of hands-on tutoring and guided self-directed learning versus selfdirected learning alone to educate critical care fellows on mechanical ventilation: a pilot project. Med Educ Online 2016; 21:32727.

8. Dreher SM, Dephilip R, Bahner D. Ultrasound exposure during gross anatomy. J Emerg Med 2014; 46:231-240.

9. Bahner DP, Adkins EJ, Hughes D, Barrie M, Boulger CT, Royall NA. Integrated medical school ultrasound: development of an ultrasound vertical curriculum. Crit Ultrasound J 2013; 5:6.

10. Fox JC, Chiem AT, Rooney KP, Maldonaldo G. Web-based lectures, peer instruction and ultrasound-integrated medical education. Med Educ 2012; 46:1109-1110.

11. Fodor D, Badea R, Poanta L, Mircea P, Buzoianu AD. The use of ultrasonography in learning clinical examination: a pilot study involving third year medical students. Med Ultrason 2012; 14:177-181.

12. Brown B, Adhikari S, Marx J, Lander L, Todd GL. Introduction of ultrasound into gross anatomy curriculum: perceptions of medical students. J Emerg Med 2012; 43:1098-1102.

13. Hoppmann RA, Rao VV, Poston MB, et al. An integrated ultrasound curriculum (iUSC) for medical students: 4-year experience. Crit Ultrasound J 2011; 3:1-12.

14. Chiem AT, Soucy Z, Dinh VA, et al. Integration of ultrasound in undergraduate medical education at the California medical schools: a discussion of common challenges and strategies from the UMeCali experience. J Ultrasound Med 2016; 35:221-233.

15. Hoppmann RA, Rao VV, Bell F, et al. The evolution of an integrated ultrasound curriculum (iUSC) for medical students: 9-year experience. Crit Ultrasound J 2015; 7:18.

16. Rao S, van Holsbeeck L, Musial JL, et al. A pilot study of comprehensive ultrasound education at the Wayne State University School of Medicine: a pioneer year review. J Ultrasound Med 2008; 27: 745-749.

17. Dinh VA, Fu JY, Lu S, Chiem A, Fox JC, Blaivas M. Integration of ultrasound in medical education at United States medical schools. J Ultrasound Med 2016; 35:413-419.

18. Accreditation Council for Graduate Medical Education. ACGME program requirements for graduate medical education in internal medicine. Accreditation Council for Graduate Medical Education website. https://www.acgme.org/Portals/0/PFAssets/ProgramRequirements/140_internal_medicine_2017-07-01.pdf Revised July 1, 2017

19. Accreditation Council for Graduate Medical Education. ACGME program requirements for graduate medical education in diagnostic radiology. Accreditation Council for Graduate Medical Education website. https://www.acgme.org/Portals/0/PFAssets/ProgramRequirements/ 420_diagnostic_radiology_2017-07-01.pdf. Revised July 1, 2017.

20. Accreditation Council for Graduate Medical Education. ACGME program requirements for graduate medical education in obstetrics and gynecology. Accreditation Council for Graduate Medical Education website. https://www.acgme.org/Portals/0/PFAssets/ProgramRequirements/220_obstetrics_and_gynecology_2017-07-01.pdf Revised July 1, 2017.

21. Accreditation Council for Graduate Medical Education. ACGME program requirements for graduate medical education in emergency medicine. Accreditation Council for Graduate Medical Education website. https://www.acgme.org/Portals/0/PFAssets/ProgramRequirements/ 110_emergency_medicine_2017-07-01.pdf Revised July 1, 2017.

22. Cortez EJ, Boulger CT, Eastin T, et al. The Ultrasound Challenge 2.0: introducing interinstitutional competition in medical student ultrasound education. J Ultrasound Med 2014; 33:2193-2196.

23. Bahner DP, Jasne A, Boore S, Mueller A, Cortez E. The Ultrasound Challenge: a novel approach to medical student ultrasound education. J Ultrasound Med 2012; 31:2013-2016.

24. Lewiss RE, Hayden GE, Murray A, Liu YT, Panebianco N, Liteplo AS. SonoGames: an innovative approach to emergency medicine resident ultrasound education. J Ultrasound Med 2014; 33:18431849 .

25. Connolly K, Beier L, Langdorf MI, Anderson CL, Fox JC. Ultrafest: a novel approach to ultrasound in medical education leads to improvement in written and clinical examinations. West J Emerg Med 2015; 16:143-148 